\title{
The Relation of the \\ Length of Lag Phase of Growth to the Synthesis of Nisin and Other Basic Proteins by Streptococcus lactis Grown Under Different Cultural Conditions
}

\author{
By A. HURST* AND G. J. DRING \\ Unilever Research Laboratory, Colworth House, Sharnbrook, Bedford
}

(Accepted for publication I6 August 1967)

\begin{abstract}
SUMMARY
A nisin-producing strain of Streptococcus lactis was grown in batch culture and at intervals during growth secondary cultures were derived from the parent culture and the length of lag of growth was estimated. Two media were used: a highly buffered 'medium 22' and an unbuffered (LTB) medium both without $\mathrm{pH}$ control and with $\mathrm{pH}$ controlled at about 6.7. In 'medium 22' the dry weight doubling time was $95 \mathrm{~min}$. and at the end of growth the $\mathrm{pH}$ was $5^{\cdot 2}$. Neutralization of the culture in this medium did not markedly affect nisin production or dry weight. The total and cell-bound nisin formed/unit dry wt of organism tended to correlate with the length of lag phase of growth. In LTB medium the dry wt doubling time was $45 \mathrm{~min}$. and the terminal $\mathrm{pH}$ was 4.5 . Of the total nisin formed $>80 \%$ was in the culture fluid when the $\mathrm{pH}$ was allowed to decrease below 6.0 ; total nisin in cultures without $\mathrm{pH}$ control did not correlate with length of lag phase of growth. Neutralization of the culture increased the dry wt of organism about threefold. Neutralization also increased the cell-bound nisin/unit dry wt organism in stationary phase and the length of lag of growth of such organisms was longer than comparable stationary-phase organisms grown in unneutralized culture. Chloramphenicol (I $\mu \mathrm{g} . / \mathrm{ml}$. medium) decreased the nisin/unit dry wt organism at stationary phase and the length of lag of growth of such cultures was shorter than in comparable cultures without chloramphenicol. Frequently the start of growth was characterized by a decrease of bio-assayable nisin and a shortening of the lag phase; these changes could be mimicked by a culture which had reached the stationary phase through glucose depletion. The characteristics of early growth were reproduced after the addition of more glucose.
\end{abstract}

\section{INTRODUCTION}

The biosynthesis of nisin is sensitive to inhibitors of protein synthesis and messenger RNA appears to be involved (Hurst, 1966a). The molecular weight of nisin was first reported to be about 7000; this figure was challenged by Bodansky \& Perlman (1964) who suggested that the molecular weight was more likely to be one third of the original estimate. However, recent work on the migration of peptides and small proteins in polyacrylamide gels (Ingram, Tombs \& Hurst, 1967) has confirmed the original estimate of 7000 . Thus both the method of biosynthesis of nisin and its molecular weight suggest that it is a small basic protein rather than a polypeptide. Growing

\footnotetext{
* Formerly A. Hirsch.
} 
cultures of the nisin-producing streptococcus synthesize nisin only before the stationary phase (Hurst, I966 b). These results led to the tentative conclusion that basic proteins and especially nisin have a regulatory function for Streptococcus lactis, possibly being concerned with initiation and halting of growth.

Our first growth experiments were done without control of $\mathrm{pH}$ value in batch fermentations in medium 22. This was a buffered medium in which the nisin-producing streptococcus grew slowly. We now report results in which we attempted to alter the ratio of nisin to dry weight of organism by growing the organism under $\mathrm{pH}$-controlled conditions in medium 22 and in another medium (LTB) which permits faster growth. The neutralization technique did not have much effect with the buffered medium 22 but it had considerable effect with LTB medium. Stationary-phase organisms obtained from LTB medium with $\mathrm{pH}$ control contained more nisin/dry wt organism than comparable cultures grown without $\mathrm{pH}$ control, and the length of the lag phase was increased. When chloramphenicol was added in small amounts, nisin produced/dry wt organism was decreased and, as expected, the resulting cultures had a shorter lag phase. These results support the earlier suggestion that in the nisin-producing strain of $S$. lactis the antibiotic may have a regulatory function.

\section{METHODS}

Media, organism, culture conditions, preparation of samples, estimations, extinctions, nisin bio-assay, electrophoresis and estimation of the length of lag phase of growth were all as described previously (Hurst, I966 ). As defined previously, total nisin was the amount which could be estimated by bio-assay of cocci and medium. Cell-bound nisin was the amount of nisin retained by the cocci after discarding the culture fluid.

Media. Medium 22 and the LTB medium were as described before (Hurst, I966a). Previously we used medium 22 for growth of the nisin-producing strain, and medium LTB for growing the bio-assay test organism. In the experiments in this paper both media were used for growing the nisin-producing strain; the much faster growth rate in LTB medium permitted complete growth of a batch culture in about $8 \mathrm{hr}$ as compared to about $14 \mathrm{hr}$ in medium 22 . In experiments in which the culture was maintained at $\mathrm{pH} 6 \cdot 7$, media contained $2.5 \%(\mathrm{w} / \mathrm{v})$ glucose unless otherwise stated; neutralization of the lactic acid formed by the growing cultures was by periodic addition of $10 \mathrm{~N}-\mathrm{NaOH}$ with gentle stirring to avoid aeration.

Basic proteins were prepared as described by Hurst (1966 b). Basic proteins were extracted from whole cocci with hot $0.05 \mathrm{~N}-\mathrm{HCl}$, followed by propanol extraction followed by ion-exchange chromatography on columns of Amberlite resin CG 50 (British Drug Houses Ltd., Poole, Dorset, England). Total basic protein was defined as the fraction eluted after exhaustive washing of the columns with $50 \%(\mathrm{v} / \mathrm{v})$ acetic acid in water; this was measured either by weighing or by densitometry after electrophoresis in polyacrylamide gels. Weighing tended to give an underestimate of the basic proteins because of loss of material during the manipulations involved in freezedrying. With densitometry, the concentration of basic proteins was expressed in terms of a nisin marker after staining with amido-black. Provided samples were run on the same gel and stained at the same time the results were reproducible to within $15 \%$. It was recently shown with ribosomal proteins that densitometry after staining gives the same quantitative and qualitative results as radio-activity measurements (Traut, 1966). 


\section{RESULTS}

Distribution of nisin between cocci and culture fluids in LTB medium at different stages of fermentation

During a lactic fermentation the $\mathrm{pH}$ value decreased as lactic acid accumulated and this increased the solubility of basic proteins. Figure I shows that at $\mathrm{pH}>6.0$ more than $80 \%$ of the nisin was associated with the cocci, at $\mathrm{pH}<6.0$ more than $80 \%$ was in the culture fluid.

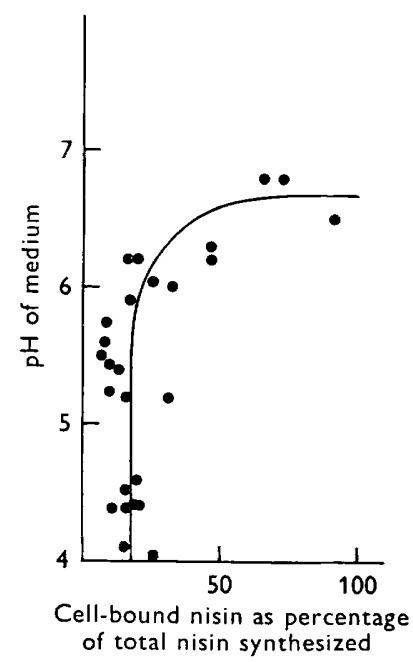

Fig. I

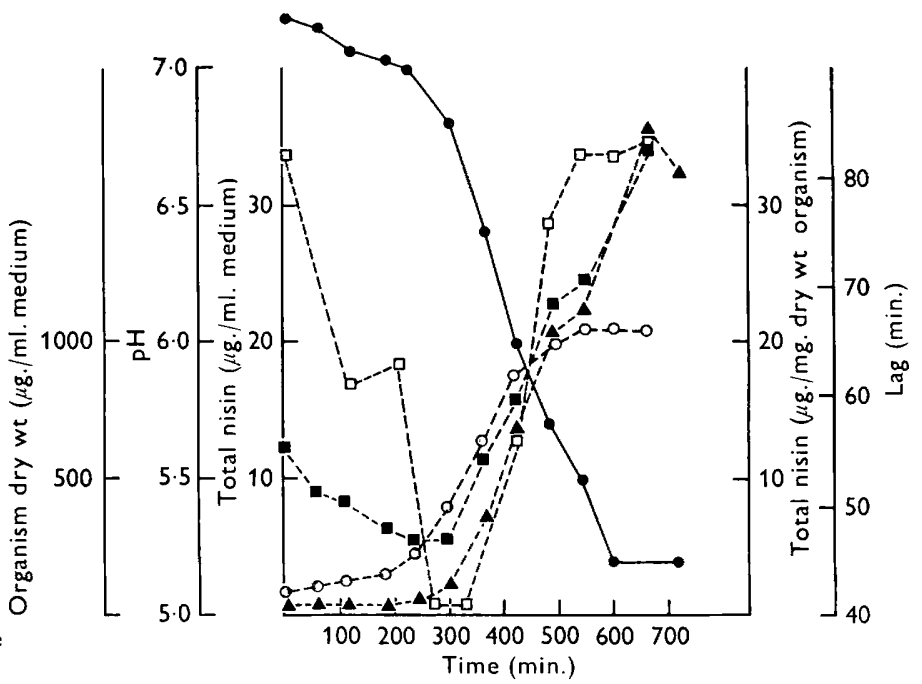

Fig. 2

Fig. I. Synthesis and binding of nisin by Streptococcus lactis as a function of the $\mathrm{pH}$ value of the medium.

Fig. 2. Growth of Streptococcus lactis in a buffered complex medium. Dry wt organism O-.-; lag $\square-.-$; total nisin $/ \mathrm{ml}$. medium $\Delta-.-$; total nisin $/ \mathrm{mg}$. dry wt. --.-; pH $\mathbf{0 -}$ The length of the lag phase of growth was estimated in LTB medium.

\section{Growth in medium 22 without $p H$ control}

An example of this type of experiment is shown in Fig. 2. The initial $\mathrm{pH} 7 \cdot 2 \mathrm{de}-$

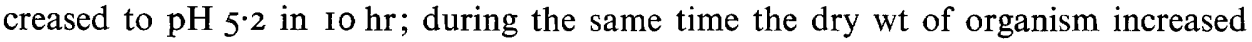
from $80 \mu \mathrm{g} . / \mathrm{ml}$. medium to $1050 \mu \mathrm{g} . / \mathrm{ml}$. During the exponential phase of growth the dry wt doubling time was $95 \mathrm{~min}$. Nisin was not synthesized during the lag phase and the nisin/unit dry wt organism decreased during this time. Coincident with this change in the nisin concentration the lag phase of growth of secondary cultures became shorter. The inoculum had a lag of $80 \mathrm{~min}$. which decreased to $40 \mathrm{~min}$. at early exponential phase. During this phase of growth nisin synthesis started and the length of lag of secondary cultures progressively increased until it returned to its original value of $80 \mathrm{~min}$. A maximum of $33 \mu \mathrm{g}$. nisin $/ \mathrm{mg}$. dry wt organism was obtained. 


\section{Growth in medium 22 with $\mathrm{pH}$ controlled to 6.7}

The initial $\mathrm{pH} 7.3$ of the medium was allowed to decrease to $\mathrm{pH} 6.7$ and then maintained at this value. The final dry wt of cocci was I $100 \mu \mathrm{g} . / \mathrm{ml}$., only slightly higher than that of the pH-uncontrolled fermentation. Nisin synthesis started after a delay of 100 min.; the inoculum had a lag of growth of I $76 \mathrm{~min}$. which decreased to $126 \mathrm{~min}$. at early exponential phase, to reach a maximum of $206 \mathrm{~min}$. at stationary phase. A maximum of $44 \mu \mathrm{g}$. nisin/mg. dry wt cocci was obtained (Fig. 3). The data of Fig. 2 and 3 have been redrawn in Fig. 4. This shows that there might be a correlation between total nisin $(\mu \mathrm{g} . / \mathrm{mg}$. dry wt cocci) and time of lag in the controlled and in the $\mathrm{pH}$-uncontrolled fermentation.

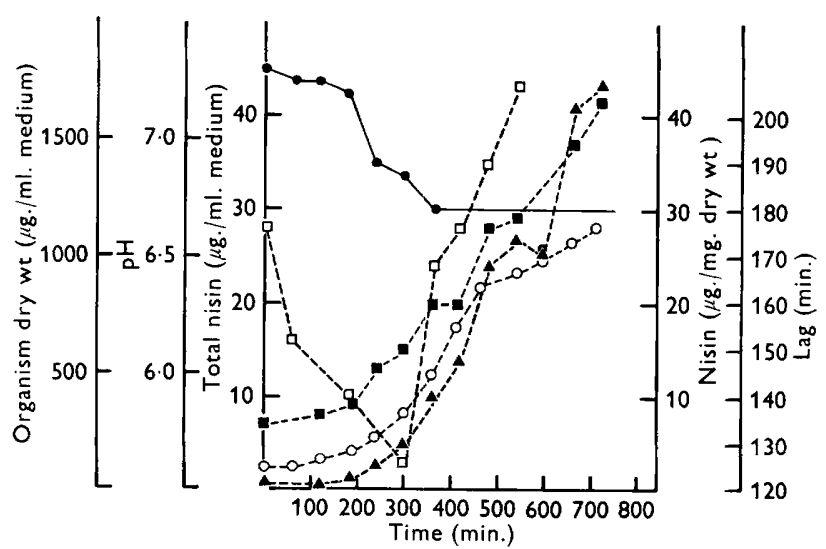

Fig. 3

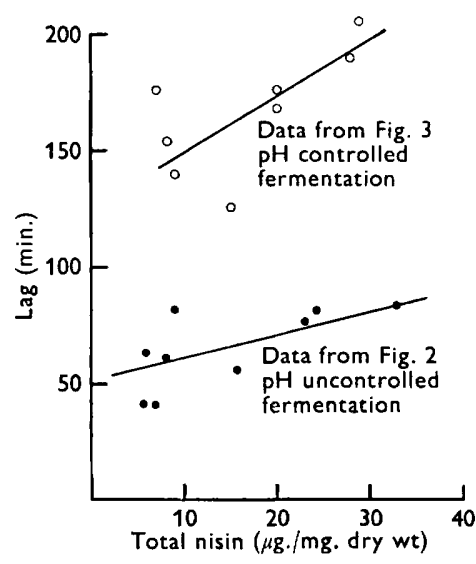

Fig. 4

Fig. 3. Growth of Streptococcus lactis in a buffered complex medium with $\mathrm{pH}$ control.

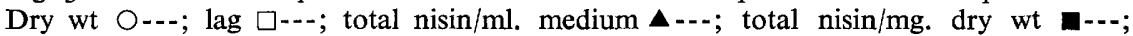
$\mathrm{pH}-$-.

Fig. 4. Correlation between length of lag and total nisin/unit dry wt cells in pH-controlled and uncontrolled fermentations in buffered medium.

\section{Growth in LTB medium with and without $p H$ control}

Figure 5 is a record of an experiment in LTB medium which enabled the organism to grow about twice as fast as in medium 22 (doubling time $45 \mathrm{~min}$.). In these experiments cell-bound as well as total nisin was estimated; the uncontrolled medium decreased from $\mathrm{pH} 6.8$ to $\mathrm{pH}_{4} \cdot 4$ in $6 \mathrm{hr}$. Fig. 5 shows that neutralization had the following effects: dry wt of stationary-phase organisms increased about threefold from $800 \mu \mathrm{g}$./ $\mathrm{ml}$. medium to $2500 \mu \mathrm{g}$. Total nisin/unit dry wt organism was higher in the uncontrolled than in the pH-controlled fermentations; cellular nisin was about the same for the first $4 \mathrm{hr}$ but at stationary phase the cellular nisin/unit dry wt organism in the $\mathrm{pH}$ controlled fermentation was about double that of the uncontrolled fermentation. Accompanying the twofold increase in cellular nisin, the length of lag increased about $2 \cdot 5$-fold. The difference in the length of lag in the $\mathrm{pH}$-uncontrolled fermentation was from 65 to $80 \mathrm{~min}$. ( $15 \mathrm{~min}$.) whereas with $\mathrm{pH}$-controlled cultures the difference was from 65 to $102 \mathrm{~min}$. ( $37 \mathrm{~min}$.).

Examination of data obtained in four separate experiments showed that total nisin 
did not correlate with length of lag of growth in $\mathrm{pH}$-uncontrolled experiments. On the other hand, cell-bound nisin and length of lag were related even in $\mathrm{pH}$-uncontrolledexperiments; to show this the data of Fig. 5 have been replotted in Fig. 6. The correlation coefficient between length of lag phase of growth and cellular nisin was highly significant $(\rho=0.886)$.

\section{Effect of inhibitors of protein synthesis on nisin synthesis by cultures of Streptococcus lactis growing in LTB medium}

Previous results in a defined reaction mixture with washed suspensions of Streptococcus lactis showed that nisin synthesis was more sensitive to inhibition than was protein synthesis (Hurst, I966a). Inhibitors of protein synthesis therefore appeared a

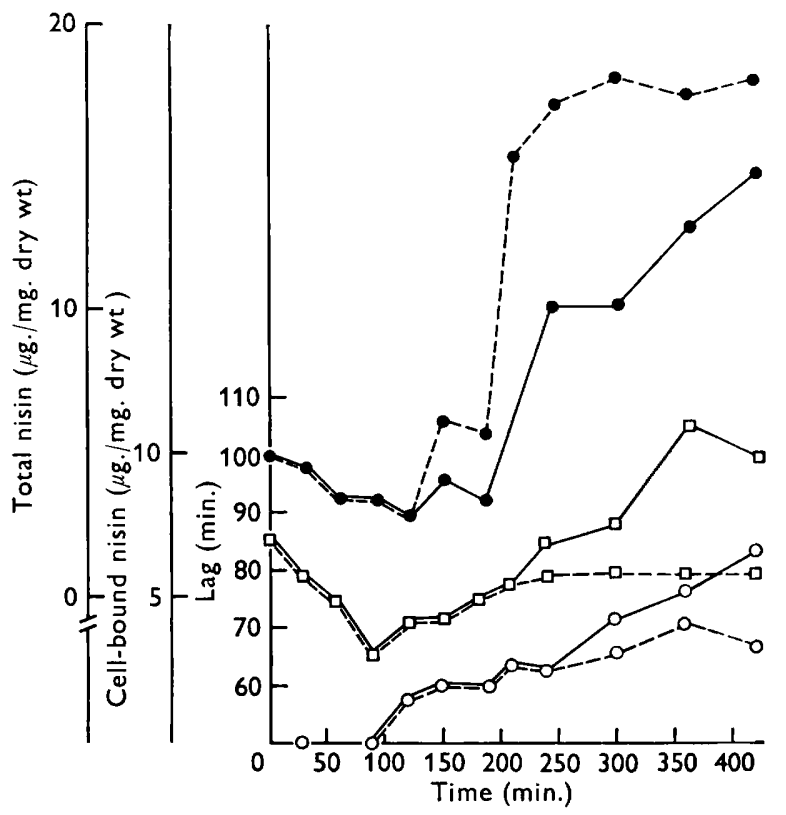

Fig. 5

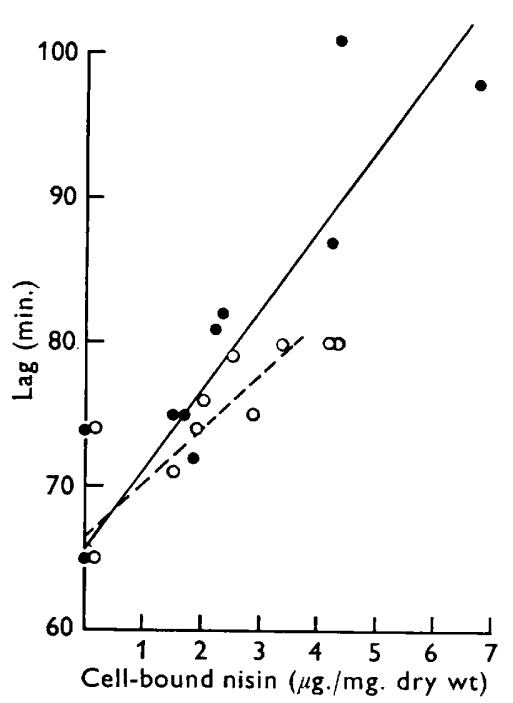

Fig. 6

Fig. 5. Total nisin and cell-bound nisin per unit dry wt of organism and length of lag of growth of Streptococcus lactis grown in LTB medium with and without $\mathrm{pH}$ control. The total nisin scale has been moved for the sake of clarity. $\mathrm{pH}$ controlled - ; $\mathrm{pH}$ unconcontrolled --.--; total nisin $\bigcirc$; cell-bound nisin $\bigcirc$; minutes of lag of growth $\square$.

Fig. 6. Correlation between cell-bound nisin and length of lag of Streptococcus lactis grown in LTB medium with and without $\mathrm{pH}$ control. $\mathrm{pH}$ controlled - $-\mathrm{pH}$ uncontrolled $\mathrm{O}-. . .$.

possible means of producing cocci with a decreased nisin content, and chloramphenicol was chosen for further work because it has the advantage of being loosely bound by ribosomes from which it can be washed off readily (Vazquez, 1966). The selective inhibition of nisin synthesis was reproduced with cultures growing in LTB medium when the chloramphenicol was added at zero time at I $\mu \mathrm{g} . / \mathrm{ml}$. medium. 


\section{Effect of chloramphenicol on nisin synthesis and length of lag phase of growth}

Chloramphenicol was tested in four experiments which gave similar results. At zero time Io 1. of inoculated culture in LTB medium was divided into two equal portions and to one portion chloramphenicol was added at $\mathrm{I} \mu \mathrm{g} . / \mathrm{ml}$. The results of one of these experiments are shown in Fig. 7. At stationary phase the control cocci contained $27 \mu \mathrm{g}$. nisin/mg. dry wt organism; the cocci grown in presence of chloramphenicol contained I I $\mu$ g. nisin/mg. dry wt organism (60\% inhibition). The length of lag of the control cocci was I $93 \mathrm{~min}$; that of the cocci grown in presence of chloramphenicol was I $32 \mathrm{~min}$. When all the data were considered, the correlation coefficient between the length of lag phase and the nisin content of control- and chloramphenicol-grown cocci was highly significant $(\rho=0.884)$.

The basic protein content of cocci obtained in another experiment is summarized in Table $\mathrm{I}$. The ratio of nisin to other basic proteins was lowest in the $\mathrm{pH}$-uncontrolled

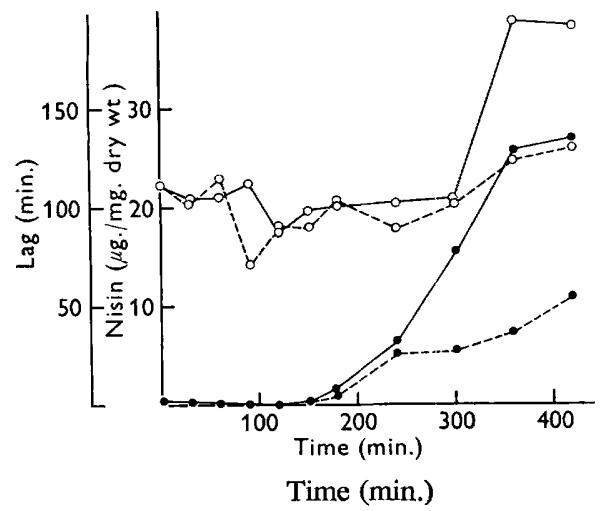

Fig. 7

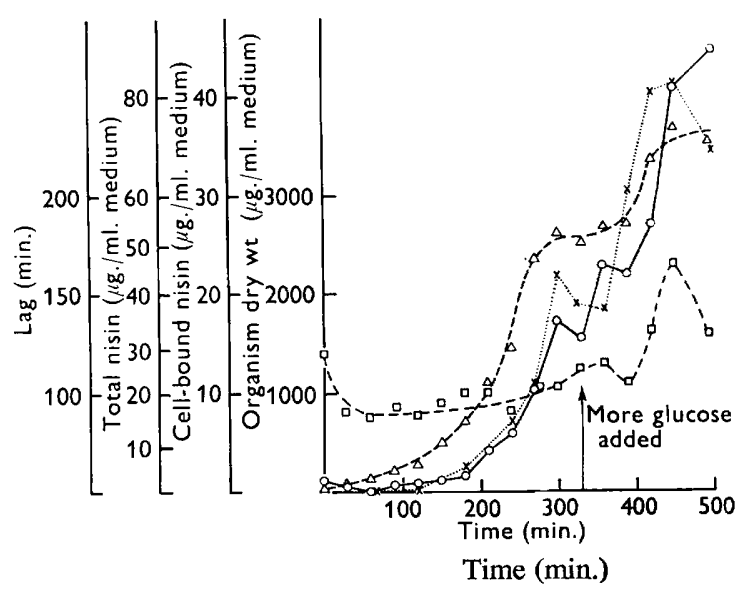

Fig. 8

Fig. 7. The effect of chloramphenicol on nisin synthesis and length of lag. Control -; chloramphenicol ----; cellular nisin $\mu \mathrm{g} . / \mathrm{mg}$. dry wt $\quad$; length of lag of growth $\bigcirc$.

Fig. 8. The effect of glucose depletion on nisin synthesis and length of lag of growth. Dry wt $\triangle---$; cell-bound nisin $\mathrm{O}-$; minutes of lag of growth $\square-\cdots$; total nisin $\times \cdots$.

Table I. Basic protein content of stationary-phase Streptococcus lactis batch-grown under different experimental conditions in LTB medium

$\begin{array}{lccc}\text { Cultural condition* } & \begin{array}{c}\text { Basic } \\ \text { protein } \\ \% \text { of } \\ \text { dry } \\ \text { weight }\end{array} & \begin{array}{c}\text { Nisin } \\ \% \text { of } \\ \text { dry } \\ \text { weight }\end{array} & \begin{array}{c}\text { Nisin } \\ \% \text { of } \\ \text { basic } \\ \text { protein }\end{array} \\ \begin{array}{l}\text { I control } \\ \text { pH control }\end{array} & 3.4 & 0.22 & \text { I5 } \\ \text { pH control +chloramphenicol } & 2.6 & 0.75 & 2 \text { I } \\ \end{array}$

* Chloramphenicol was used at $\mathrm{I} \mu \mathrm{g}$. $/ \mathrm{ml}$. of medium added before inoculation. Basic proteins were estimated by densitometry after polyacrylamide gel electrophoresis as described under 'Methods'. 
fermentation and these cocci also had the lowest total content of basic proteins. In the $\mathrm{pH}$-controlled fermentation nisin was the same $\%$ of the basic protein whether or not chloramphenicol was used. However, chloramphenicol inhibited the synthesis of all basic proteins by $26 \%$.

\section{Growth in LTB medium with $\mathrm{pH}$ control with limiting glucose}

When the glucose concentration was decreased to $\mathrm{I} \cdot 5 \%(\mathrm{w} / \mathrm{v})$ and LTB medium was used for $\mathrm{pH}$-controlled fermentation, glucose became exhausted and growth stopped after $5 \mathrm{hr}$ (Fig. 8). At this time more glucose was added to bring the total concentration to that normally used. At inoculation the lag was about $120 \mathrm{~min}$., which decreased to about $90 \mathrm{~min}$. at the beginning of the exponential phase. It increased to the original value when glucose became exhausted; after addition of more glucose growth was resumed and the lag decreased to $102 \mathrm{~min}$.; and at the end of the experiment at 495 min., the lag again increased to I $30 \mathrm{~min}$. The time course of the nisin biosynthesis followed that of the length of lag of growth. Cellular nisin present at time zero was not detected again until the lapse of $60 \mathrm{~min}$. It increased to about $\mathrm{I} 7 \mu \mathrm{g} . / \mathrm{ml}$. medium when glucose became exhausted and then increased irregularly until growth was resumed. At the end of growth the concentration reached was $45 \mu \mathrm{g} . / \mathrm{ml}$. medium. The synthesis of total nisin followed a time course which was also close to the length of lag (Fig. 8).

\section{DISCUSSION}

The evidence presented here supports the suggestion (Hurst, 1966 b) that nisin and other basic proteins are synthesized for cellular-control purposes in the Streptococcus lactis strain which produces it. The length of time to growth initiation (lag phase) was correlated with the nisin content of the organisms.

Two media were used; in the buffered medium 22 total nisin or cell-bound nisin tended to correlate with length of lag. Keeping the cultures at constant $\mathrm{pH}$ value did not change greatly the yield of organism or the nisin content of the organisms. In the unbuffered LTB medium, however, the results were more striking. The growthlimiting effect of the acidity which developed in this medium was removed by periodic neutralization. This enabled the culture to continue growth when the pH-uncontrolled culture had already reached stationary phase. The nisin/unit dry wt organism approximately doubled, and such cultures showed a longer lag phase (Fig. 5). With chloramphenicol we succeeded in reversing this situation and obtained cocci which contained less nisin/unit dry wt organism than did control cocci; such cultures had a shorter lag phase (Fig. 7). When cultures were grown with limiting glucose and more glucose was added at about stationary phase, growth was resumed and changes in nisin and length of lag phase occurred which were similar to those observed during the lag and early exponential phase (Fig. 8).

In uncontrolled LTB medium cell-bound nisin rather than total nisin correlated with length of the lag phase (see Fig. 8). Lack of correlation could be due to most of the nisin being in the culture fluid and not being cell-bound (Fig. I). When the $\mathrm{pH}$ was controlled total nisin could also correlate with length of lag (see Fig. 8). Even so, the correlation between cellular nisin and length of lag phase was not perfect. In the course of normal growth most of the nisin is excreted; when the culture is grown with $\mathrm{pH}$ control most of the nisin is probably non-specifically bound. Thus cellular nisin may 
have two components, a non-specifically bound part and an additional functional form; the bio-assay does not distinguish between these two forms. It is possible that the other basic proteins play a part in cellular-control mechanisms. This also appears rather likely since nisin forms only about $20 \%$ of the total basic proteins (Table I) and attention has so far been focused on it simply because of the ease of estimating it by bio-assay.

It is interesting to note that the composition of the cell could be altered by the cultural conditions used (Table I). Leaver \& Cruft (1966) found that the basic proteins of Bacillus megaterium and Escherichia coli constituted up to I \% of the dry weight of the organisms. We have found similar figures for our nisin-producing organism when grown without $\mathrm{pH}$ control. The changes in the cell composition were in concordance with the length of the lag phase of growth, confirming our earlier suggestion that nisin had a regulatory function. Not all strains of Streptococcus lactis produce nisin, so that the regulatory function is either unimportant or nisin-like molecules are more widely distributed than has been appreciated so far. A small survey of different strains of $S$. lactis showed that nisin production was the norm, and strains which did not produce nisin produced, nevertheless, small molecular weight basic proteins which resembled nisin by Sephadex chromatography and electrophoretic behaviour (Hurst 1967).

It is hoped that this work will draw attention to the possible importance of smallmolecular-weight basic proteins. They may or may not be antibiotics and are widely distributed within the Streptococcus lactis species. In one strain we have shown a probable correlation between length of lag phase of growth and basic protein content of the organism. We have not yet shown whether these phenomena are causal or coincidental.

We wish to thank Mr M. Pugh for estimations of nisin and Miss M. Hirst for calculation of correlation coefficients.

\section{REFERENCES}

Bodansky, M. \& Perlman, D. (1964). Are peptide antibiotics small proteins? Nature, Lond. $204,840$.

Hurst, A. (1966a). Biosynthesis of the antibiotic nisin by whole Streptococcus lactis organisms. J. gen. Microbiol. 44, 209.

HuRst, A. (1966b). Biosynthesis of the antibiotic nisin and other basic peptides by Streptococcus lactis grown in batch culture. J. gen. Microbiol. 45, 503.

Hurst, A. (1967). Function of nisin and nisin-like basic proteins in the growth cycle of Streptococcus lactis. Nature, Lond. 214, 1232.

Ingram, L., Tombs, M. P. \& Hurst, A. (1967). Mobility, molecular weight relationships of small proteins and peptides in acrylamide gel electrophoresis. Analyt. Biochem. 20, 24.

LeAver, J. L. \& CRUFT, H. J. (I966). Investigation into the distribution and properties of histones and other basic proteins in bacteria. Biochem. J. Ior, 665 .

TraUT, R. R. (I966). Acrylamide gel electrophoresis of radio-active ribosomal protein. J. molec. Biol. 2I, 57 I.

VAZQUEZ, D. (I966). Mode of action of chloramphenicol and related antibiotics. Symp. Soc. gen. Microbiol. 16, 169. 